\title{
University of the Sunshine Coast and Deakin University
}

\author{
Ross Watkins and Maria Takolander
}

\section{Introduction: Writing and gaming}

We have entered the age of gaming and gamification, and creative writing - as both a cultural practice and a discipline of study - is being drawn into this phase of digital culture. Despite the bookish backlash noted by Adam Hammond in Literature in the digital age (2016), major publishers have begun to experiment with interactive digital narratives. Penguin's We tell stories (2008) was a first attempt by a major publisher to future-proof its business through a merging of gaming principles and creative writing - an attempt more recently repeated by Hachette's New star soccer story 'game book' (2016). In 'The shifting author-reader dynamic', R. Lyle Skains diagnoses such experiments in relation to the consumer reality: 'The next generation of readers is currently in their teens, spending far more attention, time, and money on digital platforms such as gaming and internet interactions than they do in any other entertainment genre' (2010: 96). However, while literature is being challenged to adapt in a digital age increasingly dominated by gamers, the traffic is not just one-way. Games are also changing in response to literary or artistic imperatives, as writers are conscripted into development teams in an increasingly competitive games industry, and as scholars focus their attention on games as artefacts of cultural interest. While some early game scholars aggressively opposed the ludic culture of gaming to the readerly culture of literature, and while the agency of players (as opposed to the assumed passivity of readers) often continues to be lauded as the distinguishing virtue of games, hard-and-fast distinctions are being eroded. Astrid Ensslin, for example, while remaining appropriately sensitive to medium specificities, has posited the emergence of the hybrid form of the 'literary game' (2014), exemplified by such work as Tale of Tale's The Path (2009).

In Electronic literature: New horizons for the literary (2008), N Katherine Hayles considers the new types of readers and reading practices that are emerging in the digital age. This special issue of TEXT considers the new forms of writers and writing practices that are emerging in our digital age, paying specific attention to the various convergences of writing practices with cultures of gaming. Creative writers, often working in team environments to design immersive multimedia narratives for a digital medium, are establishing new forms of authoring and authorship. The nature of these new writing practices also defamiliarises traditional writing practices (in print, for instance) in ways that can prove enlightening for practitioners and scholars interested in how creative writing emerges in relation to older technologies. In addition, given the transmedial nature of our cultural economy, games writing inevitably exists in dynamic correspondence with other writing practices, including adaptation, games journalism 
and academic analysis. As Janet Murray argues, speaking back to the 'unproductively sectarian discourse' that characterised the earlier narratology versus ludology debate, we 'should no longer be confused by the appearance of an either/or choice between games and stories' (2013). They are, she declares, 'interpenetrating sibling categories, neither of which completely subsumes the other' (2013). It is an understanding of creative writing and videogames that this special issue of TEXT has attempted to uphold and explore.

The papers in this special issue address four main themes: academia and authorship; authoring and authorship; agency and authorship; and adaptation and authorship.

\section{Academia and authorship}

Leena van Deventer's 'Teaching Writing for Videogames' explores the unique challenges that arise when teaching creative writing for non-linear and ludic contexts: from the cultural anxiety attached to the cultural and political value, and the social impact of videogames, to tension between notions of work and play, and to the influence of other storytelling pedagogies on interactive narrative students. Using her experience as an educator within this fast-emerging field, van Deventer then traces the challenges faced by interactive narrative students within a literacy environment that empowers them to blur the lines between author, reader and player, arguing for reformation in how writing for videogames is taught, one that is distinct from traditional pedagogies of creative writing.

Dan Golding's 'Writing games: popular and critical videogame writing over time' presents a chronological and developmental overview of critical games studies writing within, without and between scholarly and non-scholarly publication platforms, and in doing so presents a view of not only how videogames are popularly understood, but also the position of the voices contributing to the body of knowledge. In stepping through the forms of videogame research dissemination - from blog and social media platforms, magazines, YouTube, long-form monographs, to peer-reviewed journals Golding teases out the political and social tensions that exist between academia and popular writing.

\section{Authoring and authorship}

Maria Takolander's 'What games writing teaches us about creative writing: A case study of The Fullbright Company's Gone Home' destabilises the idea of creativity as a monolithic activity. Using Vlad Petre Glăveanu's research on the social psychology of creativity - based on the analysis of Romanian Easter-egg decoration - Takolander presents the phenomenon of authorship as an emergent event resulting from the dynamic interaction of a creative subject/s, a social and cultural context, and the material artefact. She exemplifies this via a case study of the multi-award-winning game Gone Home (2013), informed by an interview with The Fullbright Company's Steve Gaynor. The article concludes with a reflection on the ramifications of Takolander's findings - and games writing principles more generally - for creative writing. 
In 'All the Delicate Duplicates: Game building with[in] Mezangelle', Mez Breeze tracks the conceptual origins, commissioning process, precedents, collaborative development and reception of All the Delicate Duplicates, a non-linear narrative that combines visual, audio, and text-based elements created using Mezangelle. Mezangelle involves the creation of sentences and phrases designed to disrupt traditional poetic construction by remixing the basic structure of English and computer programming code.

In 'Branched and parsed: The tools of interactive narrative writing', Katryna Starks identifies that there is little research to bridge the gap between creative writing knowledge and coding practice to help creative writers become interactive narrative developers. Drawing on Hartmut Koenitz's recommendation for a unified vocabulary to assist writers working with interactive narrative authoring systems, Starks presents a survey of research on interactive narrative content and structure, including analyses of four authoring tools.

Dakoda Barker's 'A story without words: Challenges crafting narrative in the videogame Rise' explores the methodologies involved in authoring Rise, a videogame vignette designed to impart the experience of a chronic health condition on the game's player. Barker explores the tensions between ludic and narratological game design decisions - from quicktime events, to linear and non-linear structures, and the creation of verisimilitude and immersion - and the opportunities created for player-character actions to form a player's meaningful engagement within a wordless narrative.

\section{Agency and authorship}

In 'Connecting player and character agency in videogames', Alayna Cole considers the intersection of games studies and creative writing vis-à-vis notions of agency, and the impact of these notions on narrative outcomes, particularly in relation to contesting perceptions of the significance of player agency or authorial intention in videogames. Calling for further research at this point of intersection, as well as analysis of how this intersection impacts knowledge within each of the fields explored, Cole canvasses current theories on agency in videogames and creative writing, arguing for a wider conception to differentiate the variety of agency forms and functions, and that these concepts can coexist in meaningful ways.

Brooke Maggs, in 'Surveying VR storytelling: Investigating key terminology and the role of the procedural author', reassesses the concepts of immersion, presence, interactivity, and agency in relation to narrative storytelling in the virtual reality space. As each domain - creative writing and interactive technology development - defines these terms in ways specific to the inherent medium, tension arises within an industry context when storytellers are brought together with software developers. Maggs teases out these differences but concludes with a point of connection: that technology and narrative coincide at the body.

Matthew S. S. Johnson's 'Building the character: Imagined consciousness in roleplaying videogames' interrogates the illusion of player agency and the claim that players become coauthors with game designers/writers on the narrative unfolding. 
Johnson acknowledges the way videogames complicate authorial and readerly relationships, arguing that reader/players revise traditional concepts of authorship, relocating it to spaces where creative/inventive desires and readerly roles intersect with game design parameters. Johnson draws attention to the illusions, contradictions and negotiations of gameplay authorship, and the paradox that, in roleplaying videogames, the limitation of creative agency simultaneously motivates agency and makes it apparent.

\section{Adaptation and authorship}

In 'Waking up as Alan: game novelisation and the player-reader-writer', Ross Watkins explores the overlaps and gaps between playing as Alan Wake in the videogame (Alan is a best-selling genre fiction novelist who finds himself embedded in his own horror story), reading Rick Burroughs's subsequent novelisation of the videogame, and writing Alan Wake fan fiction. Written in a fictocritical mode, the article is as much performance as it is a critical investigation into the tensions between each narrative position (player-reader-writer), with each viewpoint and interactive form regarded for its unique ability to generate narrative immersion.

Rhett Davis's 'Making it old and new: Intermedial print-digital approaches to the novel as response to media competition' considers the current state of the analogue novel within our digital media-saturated context. Following a succinct survey of the history of the way the novel form has undergone remediation, Davis turns his attention to Steven Hall's The Raw Shark Texts and Jennifer Egan's A Visit from the Good Squad, exemplars of the intermedial print-digital novel (or augmented book) that, Davis argues, may offer an ideal approach to bridging the gap between print and digital fiction, and help point the way to a future literature where print and digital media co-exist.

\section{Acknowledgements}

This special issue would not be as rich and rigorous without the curatorial and editorial assistance of Alayna Cole and Rhett Davis. Warm thanks to you both for your generosity of time, effort and spirit. 


\section{Works cited}

Ensslin, Astrid 2014 Literary gaming London: The MIT Press

Hammond, Adam 2016 Literature in the digital age New York: Cambridge University Press

Hayles, N Katherine 2008 Electronic literature: New horizons for the literary Notre Dame (Indiana): University of Notre Dame

Murray, Janet H. 2013 'The last word on ludology v narratology in game studies'

https://inventingthemedium.com/2013/06/28/the-last-word-on-ludology-v-narratology-2005/ (accessed 8 March 2018)

Skains, RL 2010 'The shifting author-reader dynamic: Online novel communities as a bridge from print to digital literature' Convergence: The international journal of research into new media technologies 16.1: $95-111$

Dr Ross Watkins is an author and illustrator for both children and adults. One Photo was shortlisted for the 2017 CBCA Picture Book of the Year, and The Boy Who Grew Into a Tree was shortlisted for the 2013 Aurealis Award for Speculative Fiction. His debut adult novel, The Apology, is due for release August 2018. Ross' scholarly research explores practices in illustrated narrative, representations of grief, adaptation and transmediation, and radical modes of scholarly writing.

Maria Takolander is an Associate Professor in Writing and Literature at Deakin University in Geelong, Victoria. She is the author of numerous papers theorising creativity (in relation to mental illness, embodied cognition and sociomaterial practice) as well as essays on Australian and international magical realist fiction. She is also a prize-winning fiction writer and a widely translated and anthologised poet. The Double (and other stories) (Text 2013) was a finalist in the 2015 Melbourne Prize for Literature. Her most recent book of poems is The End of the World (Giramondo 2014). 